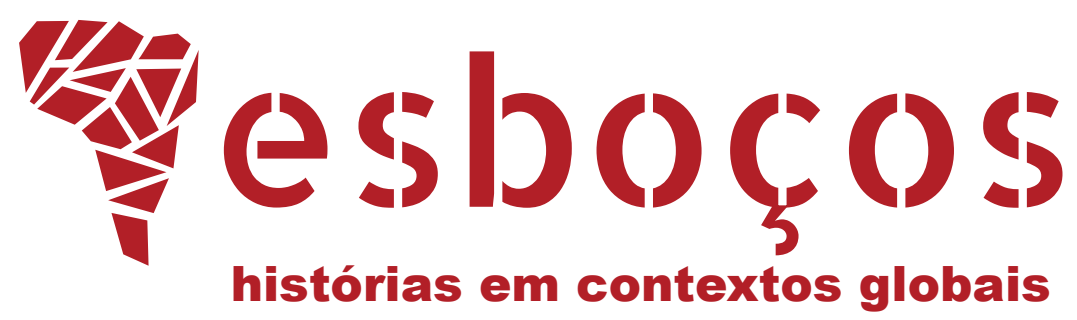

\title{
HISTÓRIAS CONECTADAS DA IDADE MÉDIA: ABORDAGENS GLOBAIS ANTES DE 1600
}

Connected Histories of Middle Ages: Global Approaches Before 1600

Cláudia Regina Bovoab (D) https://orcid.org/0000-0002-4201-713X E-mail: claudia.bovo@uftm.edu.br

Adrien Bayard ${ }^{\mathrm{cb}}$

(1) https://orcid.org/0000-0002-0886-0799

E-mail: adrien.bayard@univ-artois.fr

a Universidade Federal do Triângulo Mineiro, Instituto de Educação, Letras, Artes, Ciências Humanas e Sociais, Departamento de História, Uberaba, MG, Brasil

• Organizador do dossiê "Histórias conectadas da Idade Média"

‘ Université d'Artois, Centre de Recherche et d'Études - Histoire et Sociétés, Arras, France

DOSSIÊ

Histórias conectadas da Idade Média 
$s$ últimas décadas do século $X X$ foram marcadas por mudanças estruturais rápidas no cenário mundial. Seja pelas transformações geopolíticas provocadas com a descolonização da África e da Ásia (1960-1970) ou pelo fim da Guerra fria (1990), seja pelo avanço da globalização e da expansão do desenvolvimento tecnológico, uma demanda por histórias transnacionais emergiu enquanto fruto de um mundo cada vez mais interdependente. A partir da consolidação de associações econômicas, políticas e culturais, os limites impostos por visões de mundo nacionalistas e abordagens acadêmicas eurocêntricas trouxeram à tona provocações importantes sobre a necessidade de novas maneiras de interpretar e explicar as experiências históricas a partir do viés global.

Novas abordagens historiográficas surgiram dessa seara, que apesar de ter na década de 1990 o momento de constituição formal do campo, com institucionalização efetiva de associações (World History Association) e periódicos, encontrou o germe de sua essência na ousadia de enfoques historiográficos anteriores (BLOCH, 1930; BRAUDEL, 1949; MCNEILL, 1963). A chamada Global History aparece em diversas ramificações, as quais, ao se construírem enquanto abordagem historiográfica, colocam à prova os melhores meios para sua realização. Como afirmou Diego Olstein (2015), apesar das sobreposições historiográficas, essas múltiplas tendências à história global compartilham características comuns e estão todas dedicadas a pensar a história por meio do que se identifica como os 4 "Ces": a conexão, a comparação, a conceituação e a contextualização.

Da história global à transnacional, as histórias conectadas estão dispostas a estabelecer abordagens sobre os cruzamentos históricos a partir da longa duração, da longa distância, da análise em múltipla escala e da transdisciplinaridade. É, justamente, nessa perspectiva que os debates em torno das conexões históricas pré-modernas se tornam necessários. Como já demonstrou Sanjay Subrahmanyam (2017), há tradições antigas e medievais de escrita da história que analisaram outras sociedades, privilegiando o estudo das interações em múltiplos espaços e tempos, bem como em diversas escalas. Temos muito a aprender com essas narrativas, sobretudo, o modo de olhar o outro abstraído do horizonte de expectativas de conceituações modernas, como aquelas sentenciadas pelos ideais oitocentistas de "povo" e "nação".

Além disso, diante de um momento histórico que encara com pessimismo o legado eurocêntrico do Ocidente, estudos que abordam a perspectiva das Histórias conectadas da Idade Média encontram espaço auspicioso para seu desenvolvimento por algumas razões. A primeira delas está em qualificar essa temporalidade, tradicionalmente atribuída à Europa ocidental, a partir do estudo de comunidades conectadas em escala suprarregional e supracontinental, incluindo abordagens em perspectiva eurasiana e africana. Essas novas abordagens buscam demonstrar a prosperidade de análises sobre a movimentação de pessoas, a circulação de ideias e materiais, bem como as intersecções de procedimentos de governança e regulação no enfrentamento de conflitos sociais e intempéries naturais comuns às diversas comunidades anteriores às grandes navegações atlânticas.

A periodização da Idade Média surge como uma categoria temporal exclusivamente europeia, de origem seiscentista, cimentada em referenciais de linearidade e progressão evolutiva da história que explicavam a consolidação atlântica das monarquias cristãs europeias (BOVO, 2017). Como afirmaram Katheleen Davis e Michael Puett (2015, p. 1), trata-se de "um processo que, em grande medida, possibilitou a ideia da Europa como uma entidade unificada e, ao mesmo tempo, 
teve o efeito de excluir a Europa Oriental e áreas não europeias da progressão antiguidade-modernidade". Nesse sentido, as abordagens globais da Idade Média poderiam recair inconvenientemente na "narrativa egocêntrica do tempo histórico europeu", reafirmando-o.

Davis e Puett ainda alertam para um risco maior de tornar a periodização tripartite e/ou quadripartite da história europeia hegemônica, ignorando sua origem e os usos interpostos a ela. Na historiografia ocidental contemporânea, a ideia de uma Idade Média dominada pela superstição, pela irracionalidade e por uma estrutura social estática tornou-se base para interpretação de sujeitos e espaços colonizados pelos territórios europeus. As colônias atlânticas e as africanas ganharam adjetivos "medievais" que justificaram a atuação dos europeus em seus territórios chamados "bárbaros e selvagens". Dessa maneira, essas características temporalizadas atribuídas à Idade Média tornaram-se mecanismos de identificação e colonização de espaços e sujeitos na chamada modernidade, ajudando até hoje a Europa e outras potências políticas à subscrever as histórias dos seus nacionalismos e do seu pretendido domínio global.

Com o fortalecimento dos discursos ultranacionalistas atuais, o "ser" medieval ainda é um recurso de identificação usado para dar apoio aos processos de extração de riquezas e destruição de ecossistemas socioambientais (GEARY, 2005). Portanto, um aspecto negativo de buscar uma Idade Média global seria o de corroborar com essa lógica narrativa. Justamente, no anseio de se distanciar dessa narrativa imperial europeia, os medievalistas, que há muito reconhecem o problema da petrificação das periodizações, vêm propondo análises que não só redefiniram o esquema de organização da história medieval, como apresentaram, pela abordagem das conexões de povos, o complexo dinamismo das sociedades anteriores aos anos 1600 (LIEBERMAN, 2003; BOUCHERON; DELALANDE, 2015).

Os críticos da história global não estão errados ao sugerir que ela corre o risco de se tornar uma nova máscara para a história imperial, visto a tradição epistemológica ocidental apoiar-se em chaves de leitura binárias e dicotômicas, tais como: racional-supersticioso, centro-periferia, progresso-atraso, entre outras. De acordo com Richard Drayton e David Motadel (2018, p. 14), "o legado da maneira como o mundo foi integrado depois de 1600, por e em resposta ao poder imperial e cultural europeu, é um eurocentrismo cognitivo incorporado em nossos métodos".

Nesse sentido, gostaríamos de enfatizar que três elementos devem ser destacados na busca por se fazer histórias conectadas da Idade Média: primeiramente, quaisquer novos empreendimentos compartilhados exigirão um esforço contínuo para superar a barreira das tradições epistemológicas cartesianas. O desafio para os historiadores é encontrar novos tipos de padrões, métodos, julgamentos de valor e, mais importante, conceitos na experiência histórica e na autoconsciência histórica desses continentes integrados. Em vez de confiar exclusivamente em estruturas interpretativas emprestadas de estudiosos de outros períodos históricos, sentimos que a tarefa premente é analisar como as conexões eurasianas e africanas foram experimentadas na Idade Média, buscando histórias medievais conectadas que façam sentido em seus próprios termos.

Atentos a isso, o presente dossiê reúne um conjunto de artigos que possuem como objeto de reflexão a abordagem das histórias conectadas. Nessa direção, o artigo "Perspectivas da história econômica global da Baixa Idade Média", de Felipe Mendes Erra (2020) tem por objetivo apresentar um modelo teórico capaz de fornecer uma 
abordagem global da Baixa Idade Média. Através da análise de caso das companhias florentinas de 1310-1340, ele busca respostas ao emaranhado de conexões econômicas de longo alcance geográfico presente num mundo essencialmente fragmentado como o da Baixa Idade Média mediterrânica.

O autor apresenta ainda uma análise historiográfica muito pertinente sobre limites e desafios de modelos teóricos presentes na história econômica, sobretudo por se preocupar em manter distante a perspectiva da história global que procura identificar, em um único elemento da vida socioeconômica, o fio condutor da investigação. Ele avança significativamente no desenvolvimento de uma abordagem própria, inspirada pela historiografia de Fernand Braudel e Immanuel Wallerstein. Ao questionar a maneira adequada de fazer história global da Idade Média, Felipe Mendes Erra busca fugir das armadilhas representadas tanto pelas teorias do sistema-mundo de Frank e Gills (1996) como pela corrente teórica da globalização. Sua reflexão conduz o medievalista para dentro da história global, destacando a necessidade de produzir uma teoria econômica capaz de explicar a formação de conexões comerciais e a interação de mercados em um universo economicamente fragmentado, como era o das urbes italianas.

Valorizar a abordagem em múltiplas escalas é outro elemento a ser destacado por aqueles que buscam fazer história conectada de temporalidades recuadas (BOVO; DEGAN, 2017). Trabalhos recentes sobre a metodologia de histórias comparativas e conectadas apontam para uma abordagem na qual é preciso prestar muita atenção às peculiaridades e conexões analisadas, sejam religiosas, políticas, econômicas, intelectuais (SANTOS JÚNIOR; SOCHACZEWSKI, 2017) e também intertextuais dos testemunhos materiais e documentais. Uma vez que as conexões e as diferenças existentes pareçam suficientemente claras, as comparações transculturais em pequena escala de fenômenos relacionados ou similares oferecem o caminho mais promissor, antes que qualquer visão abrangente possa ser explorada.

O caminho das comparações e conexões transculturais entre diferentes testemunhos textuais e seus usos é demonstrado em outros dois artigos do dossiê. Vicente Dobroruka, no artigo "Ibn Fadlan and a by-passed remark on an imaginary geographical topos: some observations on the decreasing factual credibility regarding the Caucasus area of the silk road", ao estabelecer conexões entre o imaginário e a tradição textual de viajantes árabes e persas na "Rota da Seda", evidencia como o viajante Ibn Fadlan e outros partilharam uma herança comum de referenciais geográficos, míticos e, sobretudo, religiosos (DOBRORUKA, 2020). Essa comparação transcultural pode ser mais bem assinalada na investigação da herança comum compartilhada por esses testemunhos, que parece interconectada inclusive na caracterização dos seus inimigos, como os chamados bárbaros Gogue/Magogue.

A presença desses sincretismos religiosos mítico-apocalípticos descreve um processo de duração muito longa, que envolveu toda a Eurásia entre os séculos X-XIII. Nesse sentido, o relato que Ibn Fadlan deixou é bem diferente do que foi chamado de "história universal" entre os autores da Antiguidade ou bizantinos - ele pode ser visto como parte de uma extensa tradição narrativa, concebendo um contexto global de regiões, climas e povos bastante variados.

O artigo "A coleção de Tours de Atas do Concílio de Éfeso (431): um testemunho carolíngio de ressignificação doutrinária e circulação de textos no Mediterrâneo Tardo Antigo", de Robson Murilo Grando Della Torre, também se apresenta como um exemplo bem-sucedido da abordagem conectada da Idade Média. A longa e difusa 
circulação do manuscrito de Tours da coleção de Atas do Concílio de Éfeso (431) é uma síntese de experiências históricas distintas, que numa longa duração (séculos $\mathrm{V}$ ao VIII), marcados pela multiplicidade de leituras sobre esse passado da polêmica cristológica, restaura a conectividade entre diferentes espaços do Mediterrâneo Tardo Antigo e Alto Medieval (DELLA TORRE, 2020).

A transmissão mediterrânica dessa coleção de atas demonstra a materialidade da produção de memórias e de concepções da ortodoxia cristã que diferentes grupos projetaram sobre o passado polêmico de Cirilo de Alexandria e Nestório de Constantinopla (412-431), com vistas a defender posicionamentos doutrinários de seu presente. Assim, é preciso recuar até o século $\mathrm{V}$ e se deslocar até a Ásia Menor e o Egito para compreender os eventos e posições doutrinárias evocados pelo conteúdo textual da coleção de Tours. Ao mesmo tempo, não se deve esquecer a realidade histórica da Gália carolíngia, onde foram mobilizadas as apropriações e ressignificações desse material.

Para finalizar, como último elemento dessa busca por histórias conectadas da Idade Média, é preciso ainda considerar que a construção de tais abordagens não envolve apenas questões de apuro metodológico. Aqui aparece um ponto importante, talvez o que exija mais cautela, visto que, ao se trabalhar com histórias conectadas da Idade Média, demandas de identidade ainda estão ativas política e ideologicamente. É importante deixar claro que o próprio conceito de "Ocidente", usado aqui na abertura do texto, descreve não apenas uma área geográfica que corresponde vagamente à Europa (ocidental) e ao mundo atlântico, mas uma comunidade de sentidos que subscreve certos valores, uma tradição ideologicamente comprometida com ideais civilizatórios, que quer abranger o tempo histórico de Platão à OTAN.

A narrativa-mestra de uma "ascensão do Ocidente", seja ela política, intelectual, religiosa ou econômica, tem seu berço na modernidade. Ela considera os meios de se fazer história e as produções derivadas desse ofício com fins ideologicamente comprometidos. Estarmos cientes desses usos, e torná-los visíveis para o público é a tarefa primordial para quem busca produzir histórias conectadas de temporalidades recuadas.

\section{REFERÊNCIAS}

BLOCH, Marc. Comparaison. Bulletin du Centre Internacional de Synthèse, Paris, n. 9, p. 17-35, 1930.

BOUCHERON, Patrick; DELALANDE, Nicolas. Por uma história-mundo. Belo Horizonte: Autêntica, 2015.

BOVO, Cláudia Regina. El tempo em cuestión: ubicar la Edad Media em la actualidad. Revista Chilena de Estudios Medievales, Santiago, n. 11, p. 134-155, enero/junio 2017. Disponível em: http://revistas.ugm.cl/index.php/rcem/article/ view/120. Acesso em: 15 nov. 2019.

BOVO, Cláudia Regina; DEGAN, Alex. As temporalidades recuadas e sua contribuição para a aprendizagem histórica: o espaço como fonte para a história antiga e medieval. Revista História Hoje, São Paulo, v. 6, n. 12, p. 55-76, 2017. 
BRAUDEL, Fernand. La Méditerranée et le monde méditerranéen à l'époque de Philippe II. Paris: A. Colin, 1949.

DAVIS, Kathleen; PUETT, Michael. Periodization and "The Medieval Globe": A Conversation. The Medieval Globe, v. 2, n. 1, p. 1-14, 2015. Disponível em: https:// scholarworks.wmich.edu/tmg/vol2/iss1/3. Acesso em: 21 nov. 2019.

DELLA TORRE, Robson Murilo Grando. A coleção de Tours de Atas do Concílio de Éfeso (431): um testemunho carolíngio de ressignificação doutrinária e circulação de textos no mediterrâneo Tardo Antigo. Esboços, Florianópolis, v. 27, n. 44, p. 59-77, jan./abr. 2020.

DOBRORUKA, Vicente. Ibn Fadlan and a by-passed remark on an imaginary geographical topos: some observations on the decreasing factual credibility regarding the Caucasus area of the silk road. Esboços, Florianópolis, v. 27, n. 44, p. 38-58, jan./abr. 2020.

DRAYTON, Richard; MOTADEL, David. Discussion: the futures of global history. Journal of global History, v. 13, p. 1-21, 2018. Disponível em: https://www.cambridge.org/core/services/aop-cambridge-core/content/ view/36C53116D551E0B47E42865EC8DE0C41/S1740022817000262a.pdf/ discussion_the_futures_of_global_history.pdf. Acesso em: 30 nov. 2019.

ERRA, Felipe Mendes. Perspectivas da história econômica global da baixa Idade Média. Esboços, Florianópolis, v. 27, n. 44, p. 17-37, jan./abr. 2020.

FRANK, Andre Gunder; GILLS, Barry K. (ed.). The World System. London: Routledge, 1996.

GEARY, Patrick. O mito das nações: a invenção do nacionalismo. São Paulo: Conrad livros, 2005.

LIEBERMAN, Victor. Strange Parallels: Southeast Asia in Global Context, c. 8001830. Cambridge: Cambridge University Press, 2003. 2 v.

MCNEILL, William Hardy. The Rise of the West: a History of the Human Community, with a Retrospective Essay. Chicago: University of Chicago Press, 1963.

OLSTEIN, Diego. Thinking History Globally. Londres: Palgrave Macmillan, 2015.

SANTOS JÚNIOR, João Júlio Gomes dos; SOCHACZEWSKI, Monique. História global: um empreendimento intelectual em curso. Tempo, Niterói, v. 23, n. 3, p. 483502, dez. 2017.

SUBRAHMANYAM, Sanjay. Em busca das origens da história global: aula inaugural proferida no Collège de France em 28 de novembro de 2013. Estudos históricos, Rio Janeiro, v. 30, n. 60, p. 219-240, 2017. 


\section{NOTAS}

\section{AUTORIA}

Cláudia Regina Bovo: Doutora. Professora Adjunta, Universidade Federal do Triângulo Mineiro, Instituto de Educação, Letras, Artes, Ciências Humanas e Sociais, Departamento de História, Uberaba, MG, Brasil.

Adrien Bayard: Doutor. Maître de Conférence, Université d'Artois, Centre de Recherche et d'Études Histoire et Sociétés, Arras, France.

\section{ENDEREÇO PARA CORRESPONDÊNCIA}

Cláudia Regina Bovo. UFTM - Centro de Pesquisas Prof. Aloízio Rosa Prata, Rua do Carmo, n. 100, $5^{\circ}$. andar, sala 524, 38025-000, Uberaba, MG, Brasil.

\section{LICENÇA DE USO}

Esta apresentação está licenciada sob a Licença Creative Commons CC-BY. Com essa licença você pode compartilhar, adaptar e criar para qualquer fim, desde que atribua a autoria da obra.

\section{PUBLISHER}

Universidade Federal de Santa Catarina. Programa de Pós-Graduação em História. Portal de Periódicos UFSC. As ideias expressadas neste artigo são de responsabilidade de seus autores, não representando, necessariamente, a opinião dos editores ou da universidade.

\section{EDITORES}

Alex Degan

Fábio Augusto Morales

Flávia Florentino Varella (Editora-chefe)

\section{HISTÓRICO}

Recebido em: 29 de janeiro de 2020

Aprovado em: 31 de janeiro de 2020

Como citar: BOVO, Cláudia Regina; BAYARD, Adrien. Histórias conectadas da Idade Média: abordagens globais antes de 1600. Esboços, Florianópolis, v. 27, n. 44, p. 10-16, jan./abr. 2019 